cita a reflexionar sobre nuestro trabajo. Esperemos que próximamente se traduzca al castellano.

\section{FJ. Elejabarrieta}

\section{Revista catalana de psicoanàlisi}

\section{Institut de Psicoanàlisi de Barcelona}

Es tracta d'una publicació de l'Institut de Psicoanàlisi de Barcelona que surt dues vegades l'any (primavera i tardor), des del dia de Sant Jordi de 1984. Està dedicada, fonamentalment a l'estudi de la teoria, tècnica i clínica psicoanalítiques, i alhora, resta oberta a les vinculacions interdisciplinàries $\mathrm{i}$ a les aplicacions de la psicoanàlisi, tant les incloses en la vessant medicopsicològica, com poden ser la psiquiatria, psicologia, higiene mental, medicina psicosomàtica, etc., com d'altres com la biologia, les ciències socials, pedagogia, art, literatura, epistemologia.

Aquesta revista ve a omplir un buit dins de la literatura científica catalana i, àdhuc, de l'Estat espanyol, ja que és la primera revista publicada per membres de l'Associació Psicoanalítica Internacional.

La revista està escrita en català íntegrament. Tanmateix, els editors aspiren de fer-la arribar a tots els intel-lectuals interessats que parlen una llengua romànica. Pensen que, donades les arrels comunes, el contingut de la revista serà fàcilment entenedor per a qual. sevol estudiós, sobretot donat que es tracta d'una revista cientifica on molts mots $\mathrm{i}$ idees són de coneixement comú per a la col-lectivitat científica. Per tal de facilitar la comprensió a aquests lec. tors, la revista publica resums en caste. llà $\mathrm{i}$ en anglès -aquests últims revisats per Mrs. Betty Joseph, de Londres, tam. bé colllaboradora de la revista.

Es tracta d'una revista ben presenta. da i prou extensa, que inclou diferents treballs d'autors catalans i forans, tant europeus com iberoamericans.

La ciència psicoanalítica es troba en una dinàmica constant de canvi i progrés, i calia una revista per tal d'aplegar els avenços que tenen lloc arreu del món i, alhora, recollir l'aportació específica dels psicoanalistes catalans a la in. vestigació.

Hom ha considerat essencial l'ober. tura de la revista a altres disciplines, ja que desenvolupant els ligams entre les unes i les altres podran enriquir-se mútuament, contribuir a desfer malente. sos i afavorir llur progrés.

Una de les finalitats de la revista és desenvolupar el lèxic psicoanalític català, tant maltractat fins ara. Vol ésser un punt d'unificació d'aquest vocabulari psicoanalític i servir d'estímul per a anar-lo afinant. Creiem que l'esforç de cultivar la nostra llengua en la vessant psicoanalítica és una contribució més a la normalització lingüística.

La revista es fa també ressò de l'ac. tualitat psicoanalítica, i una de les sec. cions està dedicada a donar notícia de congressos, reunions i altres activitats cientifiques.

El primer número s'obre amb una carta de Freud, on fa unes considera. cions sobre les guerres i un assaig d'estudi de les motivacions d'aquestes des d'una perspectiva psicoanalítica, en res. posta a una altra carta d'Albert Einstein sobre el mateix tema. M.V. Oliva hi fa el report de l'homenatge a M. Klein, celebrat a Barcelona, en el seu centenari. Hi ha un article d'Hanna Segal sobre el concepte de Posició, de J. Corominas sobre la funció primitiva de la mà, de 
L. Grinberg i J.F. Rodríguez sobre una pacient fronterera, de N. Abelló i M. Pérez Sánchez sobre l'observació de na. dons, i de Benito López sobre la configuració clínica que anomena adiscurs ininterromput). La revisió publicada en aquest número ha estat feta per R. Bassols i J. Coderch, i fa referència a les perversions. La secció d'aplicacions de la psicoanàlisi publica un article de J.O. Esteve sobre la psicoteràpia psicoanali. tica. La secció de lligams interdisciplinaris, un article de J. Piaget sobre l'in. conscient cognitiu i l'inconscient afec. tiu, i un de J. Freixas i J. Tizón sobre el mal enteniment entre filosofia de la ciència i psicoanàlisi. La secció de lèxic, a càrrec de J.O. Esteve, es presenta a si mateixa. En la de notícies, M. Pérez Sánchez fa història dels inicis del movi. ment psicoanalític a Barcelona.

L'esforç esmerçat per l'Institut de Psi. coanàlisi de Barcelona en editar aques. ta Revista Catalana de Psicoanálisi constitueix una de les seves millors contribu. cions a l'avenç de la ciència psicoanalitica a Catalunya.

Consell de Redacció de la Revista Catalana de Psicoanàlisi
TESIS DOCTORALS

\section{LA DISCIPLINA EN EL CONTEXTO ESCOLAR: ANÁLISIS DE MODELOS EXPLICATIVOS $Y$ APLICADOS}

\section{Concepció Gotzens Busquets}

Director: doctor Cándido Genovard Rosselló

El tema de la disciplina en la escuela, del que tanto y tan diversamente se ha hablado, se trata en este trabajo con el objeto de llegar a la elaboración de un modelo teórico, capaz de explicar las variables que intervienen y determinan. el proceso disciplinario en la situación de enseñanza-aprendizaje.

Para ello, y como tarea previa, hemos tenido que llegar a una definición de lo que es disciplina, asi como de conceptos próximos y muy relaciona. dos con este, igualmente hemos recogido, analizado y estudiado la cuestión de cuál es la opinión de los adultos sobre el tema de la disciplina escolar, esto es: qué problemas les preocupan especial. mente, cuáles son los que se observan con más frecuencia, a qué creen que se deben, qué opinan respecto a su tratamiento, etc.; cuestiones todas ellas que, a otro nivel, ayudan a dar una respues. ta a la cuestión del propio concepto y la definición de disciplina. A continuación se han estudiado todas las aportaciones existentes, desde una perspectiva bien explicativa del tema, bien aplicada; la variedad en los planteamientos, así como la falta de sistematización en relación al conjunto de trabajos, nos ha 